\title{
SYNERGISTIC AMELIORATIVE EFFECT OF Lactobacillus AND Spirulina platensis AGAINST EXPERMINTAL COLITIS IN ALBINORATS: ANTIOXIDANT, HISTOPATHOLOGICAL AND MOLECULAR STUDIES
}

\author{
Emad W. Ghazy ${ }^{1}$, Abd-Allah A. Mokhbatly ${ }^{1}$, Samah S. Keniber ${ }^{1 *}$, Khaled M. Shoghy².
}

${ }^{1}$ Clinical Pathology Department, Faculty of Veterinary Medicine, Kafrelsheikh University, Egypt, ${ }^{2}$ Anatomy \& embryology Department, Faculty of Veterinary Medicine, University of Sadat city, Egypt

*Corresponding author, E-mail: samoha.saber@yahoo.com

\begin{abstract}
Ulcerative colitis (UC) considers one of inflammatory disorders which affect colon mucosa cause a substantial burden on human day life. In the past, treatment of UC depended on aminosalicylates and antibiotics but due to their adverse side effects and incomplete effectiveness, antioxidant anti-inflammatory agents are used nowadays to ameliorate UC. The aim of this work is to evaluate the modulatory effect of Lactobacillus and/or Spirulina oral administration in acetic acid induced colitisin albino rats. Rats were divided randomly into (6) groups. $1^{\text {st }}$ group (negative control), $2^{\text {nd }}$ group (acetic acid), $3^{\text {rd }}$ group (Mesalazine) at dose $20 \mathrm{mg} / \mathrm{kg}$ orally was used as positive drug control. $4^{\text {th }}$ group (Lactobacillus) at dose $1 \times 10^{9} \mathrm{CFU} / \mathrm{rat}$ daily. $5^{\text {th }}$ group (Spirulina) at dose $500 \mathrm{mg} / \mathrm{kg}$ daily. $6^{\text {th }}$ group (Lactobacillus at dose $1 \times 10^{9} \mathrm{CFU} / \mathrm{rat}+$ Spirulina at dose $500 \mathrm{mg} / \mathrm{kg}$ ). Results revealed that the experimental colitis group showed significant increase in DAI, macroscopic damage, colon weight, colonic MDA, NO, molecular expressions (iNOS and COX-2) and significant decrease in colon length, GSH level and CAT activity. Lactobacillus and/or Spirulina supplementation revealed significant improvement in macroscopic and microscopic finding, increase antioxidant biomarkers, significant inhibitions of MDA and nitric oxide. Furthermore, significant decline in COX-2 and iNOS expressions were reported. In conclusion, the protective effects of Lactobacillus and/or Spirulina in UC are due to their ability to reduce iNOS and COX-2 expressions, increase antioxidant biomarkers and significant inhibition of lipid peroxidations. Furthermore, Lactobacillus and Spirulina have synergistic protective effect on colon tissue and could be used in combination to ameliorate UC.
\end{abstract}

Key words: colitis; acetic acid; Lactobacillus; Spirulina platensis; Mesalazine; antioxidant, anti-inflammatory.

\section{Introduction}

Inflammatory bowel disease (IBD) is a an inflammatory disorder of the gastro intestinal tract, including ulcerative colitis (UC) and Crohn's disease(CD) (1). Ulcerative colitis is restricted to the colon mucosa, while any part of the whole gastrointestinal tract can be af- 
fected in Crohn's disease (2). It's occurrence and prevalence are common in any age and different area around the world, that means its emergence global disease(3). Ulcerative colitis pathogenesis is not completely understood. There are many factors affected these diseases, including immune genetic factors (4), abnormal micro biota (5), epithelial barrier disruption, broken of intestinal microbiota and other environmental factor (6).

The most clinical signs of colitis are abdominal tenderness, bloody mucous stool, purulent stool, and relapse. Furthermore, diarrhea, interrupted digestion, loss of body weight and an extensive burden on daily life (7). These clinical manifestation were established by scoring of disease activity index (DAI) (5).

Acetic acid is considered one of the main chemical widely used animal model to induced ulcerative colitis (8). Pathogenesis, histopathological features and inflammatory mediator profile to this type of colitis is phenotypically more identical to human IBD (9).

Specialized intestinal epithelial cells (IECs) are considered the physical barrier of luminal microbiota and has important role in maintaining intestinal homeostasis. So, any disturbance in the epithelial layer and intestinal permeability lead to dysregulated intestinal immune homeostasis and lead to IBD (2). Ulcerative colitis induced an increase reactive free radicals inductions and pro-inflammatory cytokines production. Furthermore, it showed significant intestinal epithelial cells apoptosis which disintegrate intestinal mucosal and barrier function. At the same time, inducible nitric oxide synthase (iNOS) (10) and cyclooxygenase-2 (COX-2) production are increased that playing a critical function in the incidence of this disease (11).

Probiotics known as "live microorganisms when supplemented in sufficient numbers, they induce health benefits to the host "(12). Lactobacillus is considered one of probiotics species which improving the component of intestinal micro flora(13), preventing action on IBD, and relieving colic symptoms(14). Furthermore, Lactobacillus has pronounced antimicrobial effect (15) and may change gut $\mathrm{pH}$ by producing some acids which prevent growth of another pathogenic bacteria(16).

Spirulina platensis is one of marine blue green microalgae with high nutritional values(17). It is rich source for many minerals, vitamins, protein and antioxidant antiinflammatory compounds such as carotenoids, and phycocyanin pigment (18).Regarding to several effects of spirulina, it includes anticancer (19), antiviral (20), anti-allergic (21), antimutagenic (22), cytoprotective (23) and cardioprotective effects (24). Moreover it induces blood vessel-relaxing effect (25), hypocholesterolemic effect(26), hypolipidemic actions (27). In addition, hepatoprotective (28), neuroprotective, reduced concentrations of tumor necrosis factor (TNF-alpha) (29)and immune-enhancing action (30) were also reported.

In the past, treatment of UC depended on aminosalicylates, antibiotics, steroids, and immune modulators but incomplete effectiveness and their adverse side effects, natural antioxidant anti-inflammatory agents are used nowadays to ameliorate UC (10).

For that reason, the present work aimed to judge the modulatory effects of oral administration of Lactobacillus and/or Spirulina platensis in experimental colitis models in rats by estimating antioxidant parameters as well as molecular and histopathological investigations.

\section{Materials and methods}

\section{Chemicals}

Lactéal fort (Lactobacillus LB) capsules purchased from Tenth of Ramadan for pharmaceutical industries \&diagnostic reagents (Rameda), Egypt. Spirulina purchased from the Algal unit of Biotechnology (National Research Center, Dokki, and Cairo, Egypt). Marsalaz tablet purchased from Marci pharmaceutical industries El- Obour City, Egypt. Acetic acid obtained from El-Nasr Pharmaceutical Chemicals Company (Cairo, Egypt). Diethyle ether obtained from (spinreact) Spin. EDTA from (Salix). Malondialdehyde (MDA), Catalase (CAT), Nitric oxide (NO) and Glutathione reduced $(\mathrm{GSH})$ purchased from BIO- 
DIGNOSTIC Company kits-Egypt. All chemicals utilized in this study was of analytical grade.

\section{Animals and feed management}

Forty-nine male albino rats of average weight $(100 \mathrm{~g} / \mathrm{rat})$ were purchased from Animal House Colony of the Tanta Center. The rats were adapted to standard laboratory conditions (temperature $22-25^{\circ} \mathrm{C}$, relative humidity 50-60\%), rats were fed a balanced diet and water ad libitum.

\section{Experimental design}

Rats after adaptation period (2 weeks) were distributed randomly into six (6) groups (8 rats in each except control positive 9 rats). The $1^{\text {st }}$ group (negative control), received saline orally for 10 days then followed by normal saline instillation at tenth day per rectum. The $2^{\text {nd }}$ group (positive control), received saline orally for 10 days followed by $2 \mathrm{ml}$ of acetic acid (4\%) intrarectally (10)at tenth day. The $3^{\text {rd }}$ group (Mesalazine group) received $2 \mathrm{ml}$ acetic acid (4\%) rectal instillation on day 10 , then given Mesalazine orally at dose $(20 \mathrm{mg} / \mathrm{kg})$ (31)for 5days after induction of colitis. The $4^{\text {th }}$ group (Lactobacillus group) received daily Lactobacillus at dose $\left(1 \times 10^{9} \mathrm{CFU}\right)$ orally/rat (14)for 10 days, then rectal instillation of $2 \mathrm{ml}$ acetic acid (4\%) at tenth day. The $5^{\text {th }}$ group (Spirulina group) received Spirulina daily at dose $(500 \mathrm{mg} / \mathrm{kg})$ orally(32)for 10 days, then rectal instillation of $2 \mathrm{ml}$ acetic acid $(4 \%)$ at tenth day. The $6^{\text {th }}$ group (Spirulina + Lactobacillus) (combination group) oral received both Spirulina $(500 \mathrm{mg} / \mathrm{kg})$ and Lactobacillus $\left(1 \times 10^{9} \mathrm{CFU}\right)$ daily for 10 days, then rectal instillation of $2 \mathrm{ml}$ acetic acid (4\%) at tenth day. All groups were observed daily for clinical signs, mortality rate, body weights, food and water intakes of the rats from each group. The rats were sacrificed at $5^{\text {th }}$ day from induction of colitis, rats were slaughter under diethyl ether anesthesia. Colon segments were dissected, removed adipose tissue, washed with normal saline, for macroscopic and microscopic examination. Colon samples were preserved imme- diately at $-80^{\circ} \mathrm{C}$ for molecular and oxidative stress analysis.

\section{Induction of colitis}

Colitis was produced by intra-colonic administration of $4 \%$ acetic acid (2ml)(33). Through a lubricant rectal pediatric urinary catheter under low-dose of ether anesthesia. Briefly, animals were restricted from food for $24 \mathrm{~h}$ (34). The instillation site was about $8 \mathrm{~cm}$ from the anal margin into the rectum. After instillation directly rats were maintained in vertical position for about $1 \mathrm{~min}$ to prevent acid leakage (35). Animals in the group one exposed to the same practice with saline instead of the acetic acid solution.

\section{Assessment of disease activity index}

According to (36), clinical signs in colitis were determined by evaluating the disease activity index (DAI)(table 1). The disease activity index includes (stool consistency, presence of rectal hemorrhage and decrease in body weight), DAI in all the tested groups were observed daily after induction of colitis by $4 \%$ acetic acid.

\section{Assessment of scoring severity of colitis}

For macroscopic damage score (Table 2), the colon was examined visually either for adhesions or gross morphological alterations immediately after death (37).

\section{Determination of colon weight and colon length}

After separated the colon from adipose tissue and remind intestine must be determine the colon weight $(\mathrm{g})$ and colon length $(\mathrm{cm})$.

Tissue sample for histopathology and antioxidant biomarkers

Tissue specimens of colon were rapidly taking and equally divided into three parts : proximal part for molecular investigation (rapidly stored at $\left.-80^{\circ} \mathrm{C}\right)(38)$, middle part used for histopathology, and distal part of colon stored at $20^{\circ} \mathrm{C}$ and used for oxidative stress and antioxidant parameters. 
Estimation of antioxidant biomarkers of colon tissue homogenates

Prior to dissection, distal part of colon were rinsed with phosphate buffered saline (PBS) solution, $\mathrm{pH} 7.4$, containing $0.16 \mathrm{mg} / \mathrm{ml}$ heparin to get rid of any red blood cells and clot. Then tissue homogenize in 5-10 ml buffer (i.e. $50 \mathrm{Mm}$ potassium phosphate $\mathrm{pH} 7.4,1 \mathrm{Mm}$ EDTA and $1 \mathrm{ml} / \mathrm{l}$ triton $\mathrm{x}-100 / \mathrm{g}$. tissue and Centrifuge at $4.000 \mathrm{rpm}$ for $15 \mathrm{~min}$. at $4^{\circ} \mathrm{C}$. The supernatant was separated into an Eppendorf tube and was preserved at $-80^{\circ} \mathrm{C}$ into aliquots for the spectrophotometric analysis of lipid peroxidation content by Malondialdehyde (MDA)(39), nitric oxide (NO) (40), Catalase $(\mathrm{CAT})(41)$, and reduced Glutathione (GSH) estimation (42).

Detection of gene expression quantitatively by real time $P C R$

Forward and reverse primers sequence for iNOS, COX2 and $\beta$-actin genes are presented in Table 3. Tissue RNA was extracted with Trizol (total RNA isolation reagent, iNtRON Biotechnology, Inc). Complementary DNA (cDNA) was synthesized by using Oligo (dT) primer HiSenSripte TMRH cDNA synthesis kits (IntROn) as described by the manufacturer's directions. The SYBR green was performed using BIoRad IQ2 (Japan) and the following protocol was used (43).The mRNA expression levels were normalized using $\beta$ actin.

\section{Histopathological studies}

Histopathological tissues preparation and examination was done according to (44)using H\&E.

\section{Statistical analysis}

Data were presented as means \pm S.E. using one-way ANOVA followed by Newman-keuls multiple comparisons using graph pad prism 7 software. Statistical significance was acceptable to a level of $\mathrm{P} \leq 0.05$

\section{Results}

\section{Mortality rate}

Control negative group, fed on standard diet, showed no abnormal clinical signs or mortality during the whole period of experimental. Mortality rate showed in table 4. Generally, the control positive group revealed obvious increase in mortality rate (4/9) (44.4\%). Meanwhile, administration of Lactobacillus alone decreased mortality rate (2/8) (25\%). Spirulina alone also decrease mortality rate (2/8) (25\%). Furthermore, the coadministration of Lactobacillus with Spirulina led to pronounced decrease in mortality rate (1/8) (12.5\%), similar to Mesalazine group which used for ulcerative colitis treatment.

\section{Disease activity index}

The effect of Lactobacillus and/or Spirulina in experimental colitis on DAI was explained in figure1. Data demonstrated significant $(\mathrm{p} \leq$ $0.05)$ elevation in DAI in acetic acid group as compared with control one. Mesalazine group revealed insignificant decrease in DAI in comparison with control positive group. Similarly, Lactobacillus group caused pronounced decrease in DAI but this reduction was still insignificant as contrasted with control positive group. Meanwhile, Spirulina alone or in combination with Lactobacillus revealed significant $(\mathrm{p} \leq 0.05)$ improvement in DAI as matched with control positive group.

\section{Scoring severity of colitis}

The effect of Lactobacillus and/or Spirulina on macroscopic damage score was illustrated in figure 2. Data explored that significant ( $p$ $\leq 0.05$ ) increase in damage score in acetic acid positive colitis as compared with the negative none treated one. Whereas, all other treated groups reported significant $(\mathrm{p} \leq 0.05)$ reduction in score damage in comparison with the positive control group.

\section{Colon weight and length}

The effect of Lactobacillus and/or Spirulina on colon weight and colon length was showed in table 4 and figure 1 . Concerning to colon 
weight, the obtained data illustrated significant $(\mathrm{p} \leq 0.05)$ increase in the control positive group as contrasted with control negative one. On the other hand, Mesalazine group showed a decrease in colon weight but still insignificant as matched with control positive group. At the same time, simultaneous supplementation of Lactobacillus and/or Spirulina in acetic acid (4\%) induced colitis revealed a significant $(\mathrm{p} \leq 0.05)$ improvement in colon weight as compared with control positive group. Furthermore, control positive group showed significant $(\mathrm{p} \leq 0.05)$ decrease in colon length in comparison with control negative group. Meanwhile, Mesalazine group revealed a significant $(\mathrm{p} \leq 0.05)$ increase in colon length as contrasted with control positive group. Similarly, a significant $(\mathrm{p} \leq 0.05)$ increase in colon length was detected in Lactobacillus and/or Spirulina groups as matched with control positive group.

\section{Lipid peroxidation and antioxidant bi- omarkers:}

The effect of Lactobacillus and/or Spirulina on Lipid peroxidation and antioxidant biomarkers were portrayed in figure 2 . The data illustrated a significant $(\mathrm{p} \leq 0.05)$ increase in MDA and nitric oxide in colon tissue homogenate in the control positive group as compared with control negative one. Meanwhile, control positive group showed marked decrease in GSH and CAT but this decrease still statically insignificant in comparison with control negative group. Nevertheless, Mesalazine group revealed a significant $(\mathrm{p} \leq 0.05)$ decrease in MDA and NO content as contrasted with control positive group. Meanwhile, treatment by Mesalazine revealed increase in GSH and CAT but still insignificant as matched with control positive group. Regarding, Lactobacillus or Spirulina supplementation in acetic acid (4\%) induced colitis group showed a significant $(\mathrm{p} \leq 0.05)$ decrease in colon tissue content of MDA and NO as compared with control positive group. Meanwhile, increase in GSH and CAT were observed but still insignificant in contrast with control positive one.
Similarly, the co-administration of Lactobacillus with Spirulina revealed a significant $(\mathrm{p} \leq 0.05)$ decline in MDA and NO as contrasted with control positive group. On the other hand, obvious enhancement in GSH and CAT were observed as matched with control positive group.

\section{Molecular investigation}

The effect of Lactobacillus and/or Spirulina in acetic acid (4\%) induced colitis on the quantitative gene expression by real time PCR were illustrated in figure 2 . The data reflect a significant ( $\mathrm{p} \leq 0.05)$ increase iniNOS and COX2expressionin the control positive group as matched with the control negative one. On the contrary, Mesalazine group showed a significant $(\mathrm{p} \leq 0.05)$ reduction in iNOS and COX2 expression as compared with control positive group. Gastric intubations of Lactobacillus or Spirulina showed a significant $(p \leq 0.05)$ improvement in iNOS and COX2expressionin comparison with control positive group. At the same time, simultaneous administration of Lactobacillus with Spirulina showed a significant $(\mathrm{p} \leq 0.05)$ decline in iNOS and COX2 expression as contrasted with control positive group.

\section{Histopathological findings}

The effect of Lactobacillus and/or Spirulina in acetic acid (4\%) induced colitis on histopathological features was showed in figure 3. Colon of rats in control negative group demonstrated normal epithelium, intestinal glands and intestinal lumen. Colon of rats in none treated positive group (severe colitis) revealed necrosis of surface epithelial and enterocytes, deposition of irregular collagen fibers, crypt distortion, and loss of intestinal glands, mononuclear cell infiltration and apoptosis of mononuclear cell. Colon of rats in the Mesalazine group (colitis) revealed patchy mucosal necrosis, proliferation of submucosal lymphoid elements such as, lymphocytes, macrophages and plasma cells with submucosal edema and necrosis together mononuclear cell infiltration. Colon of rats in the Lactobacillus group (moderate colitis) showed mono- 
nuclear cell infiltration in the mucosa and submucosa, in addition to, congestion of submucosal blood vessels and submucosal edema. Meanwhile, Lactobacillus group showed cell infiltration between the mucosal glands with necrosis of the surface enterocytes. Colon of rats in Spirulina group (mild colitis) showed mononuclear cell infiltration in the mucosa and between the mucosal glands, edema in tunica muscularis, and normal surface epithelium. Colon of rats in Lactobacillus with Spirulina group (mild colitis) showed only mononuclear cell infiltration between the mucosal glands with normal surface epithelium.

Table 1: Scoring of disease activity index (DAI)

\begin{tabular}{llll}
\hline Score & Weight loss $\%$ & Stool consistency & Occult/gross bleeding \\
\hline 0 & 0 & Normal & Normal \\
1 & $1-5 \%$ & - & - \\
2 & $5-10 \%$ & Loose stools & Occult blood \\
3 & $10-15 \%$ & - & - \\
4 & $>20 \%$ & diarrhea & Gross bleeding+ mucous \\
\hline
\end{tabular}

Table 2: Primers used for $\mathrm{qPCR}$

\begin{tabular}{lll}
\hline Gene & primer sequence $\left(5^{\prime}-----3^{\prime}\right)$ & Reference \\
\hline \multirow{2}{*}{ iNOS } & F:CCTCCTCCACCCTACCAAGT & (Villarán et al., 2010) \\
& R: CACCCAAAGTGCTTCAGTCA & \\
\multirow{2}{*}{ COX2 } & F:TGCGATGCTCTTCCGAGCTGTGCT & (Bhatia et al., 2008) \\
& R:TCAGGAAGTTCCTTATTTCCTTTC & \\
\multirow{2}{*}{-actin } & F: TGTGATGGTGGGAATGGGTCAG & (Villarán et al., 2010) \\
& R: TTTGATGTCACGCACGATTTCC & \\
\hline
\end{tabular}

Table 4: colon lesion parameters (mean $\pm \mathrm{SE}$ ) in control and different treated groups

\begin{tabular}{|c|c|c|c|c|c|c|}
\hline $\begin{array}{c}\text { Groups } \\
\text { parameters }\end{array}$ & C-ve & C+ve & M & $\mathrm{L}$ & $\mathrm{S}$ & $\mathrm{L}+\mathrm{S}$ \\
\hline Mortality rate\% & $0 \%$ & $44.4 \%$ & $12.5 \%$ & $25 \%$ & $25 \%$ & $12.5 \%$ \\
\hline $\begin{array}{ll}\begin{array}{l}\text { Body } \\
\text { change }\end{array} & \text { weight } \\
\end{array}$ & $104.2 \pm 2.392^{\mathrm{a}}$ & $81.6 \pm 1.97^{\mathrm{b}}$ & $103 \pm 2.43^{\mathrm{a}}$ & $102.9 \pm 1.96^{\mathrm{a}}$ & $93 \pm 2.77^{\mathrm{a}}$ & $95.5 \pm 3.6^{\mathrm{a}}$ \\
\hline Colon weight & $1.28 \pm 0.09^{\mathrm{b}}$ & $1.7 \pm 0.15^{\mathrm{a}}$ & $1.45 \pm 0.08^{\mathrm{ab}}$ & $1.36 \pm 0.08^{\mathrm{ab}}$ & $1.43 \pm 0.13^{\mathrm{ab}}$ & $1.4 \pm 0.04^{\mathrm{ab}}$ \\
\hline Colon length & $14.54 \pm 0.20^{\mathrm{a}}$ & $12 \pm 0.58^{\mathrm{c}}$ & $13.2 \pm 0.2^{\mathrm{b}}$ & $13.75 \pm 0.48^{\mathrm{ab}}$ & $13.67 \pm 0.33^{\mathrm{ab}}$ & $13.8 \pm 0.37^{\mathrm{ab}}$ \\
\hline $\begin{array}{l}\text { weight/length } \\
\text { ratio }\end{array}$ & $0.09 \pm 0.01^{\mathrm{b}}$ & $0.15 \pm 0.02^{\mathrm{a}}$ & $0.11 \pm 0.0^{\mathrm{b}}$ & $0.10 \pm 0.01^{\mathrm{b}}$ & $0.11 \pm 0.02^{\mathrm{b}}$ & $0.10 \pm 0.01^{b}$ \\
\hline
\end{tabular}

C-ve: Control negative, C+ve: Control Positive, (M): Mesalazine group, L: Lactobacillus group, SP: Spirulina group, L+SP: Lactobacillus + Spirulina. Data were statistically analyzed as mean \pm SEM. Rows carrying different superscript letters are significantly different at $\mathrm{p} \leq 0.05$. 


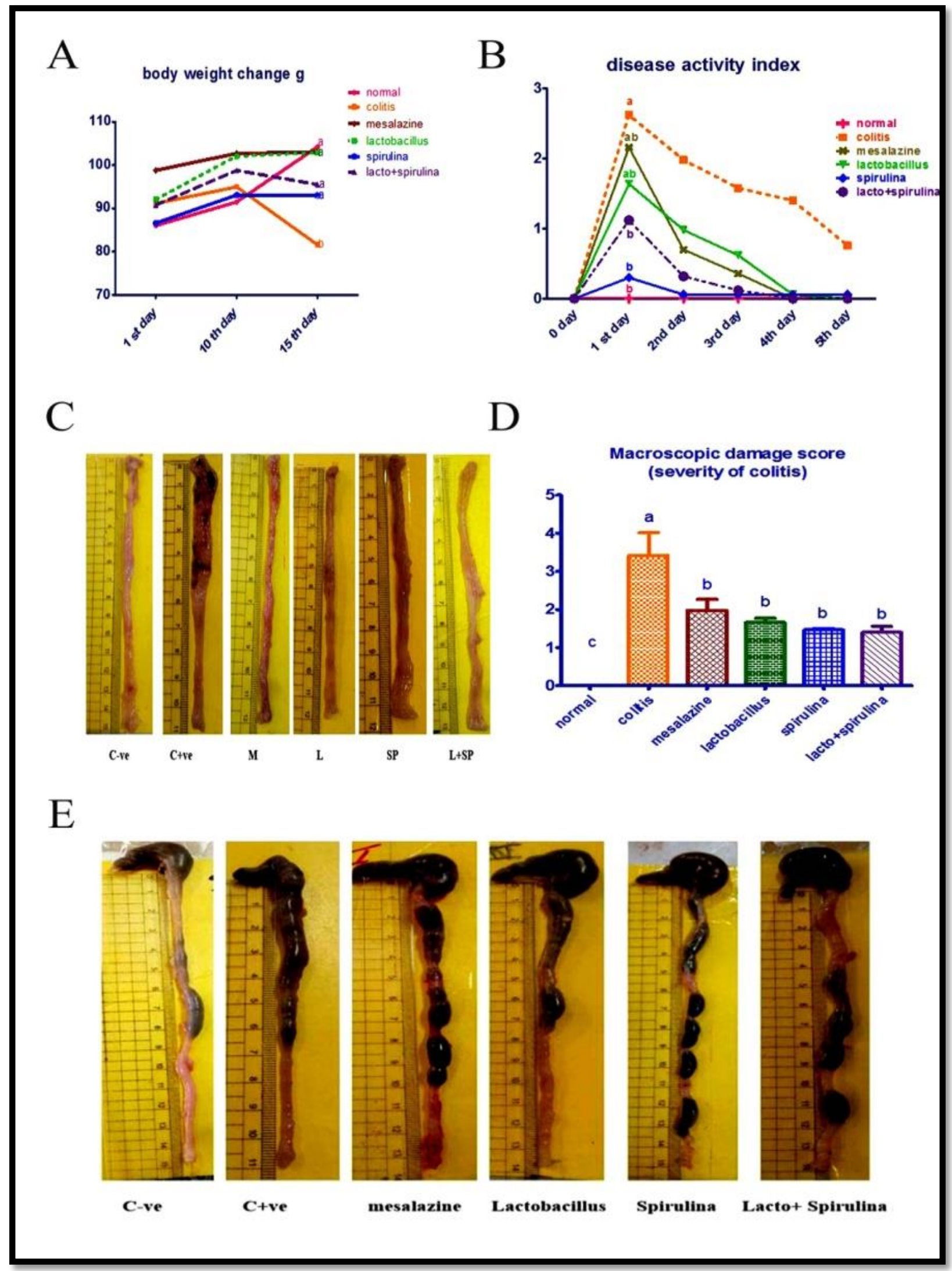

Figure 1: A) refer body weight change (g), B) disease activity index, C) Macroscopic damage in control and different treated groups, D) Colon length in control and different treated groups 
A

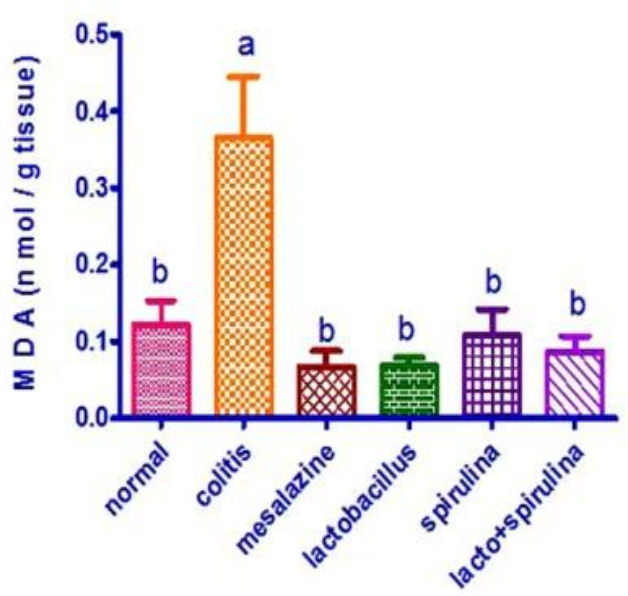

$\mathrm{C}$

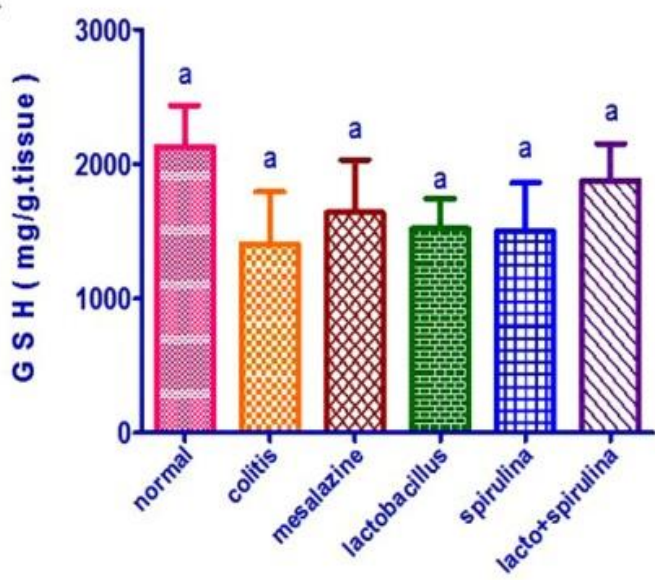

$\mathrm{E}$

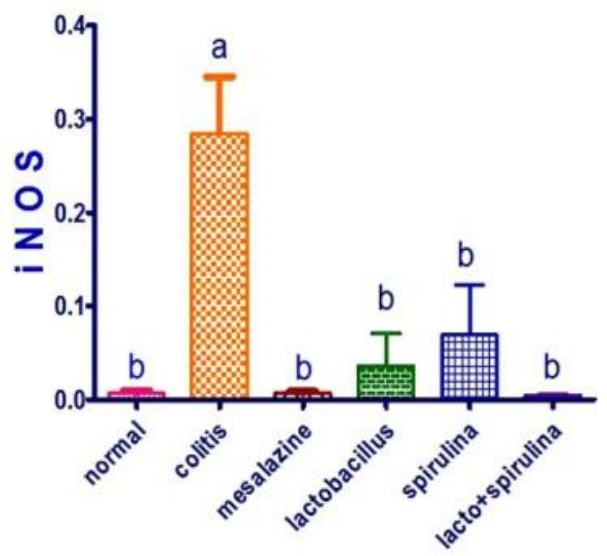

B

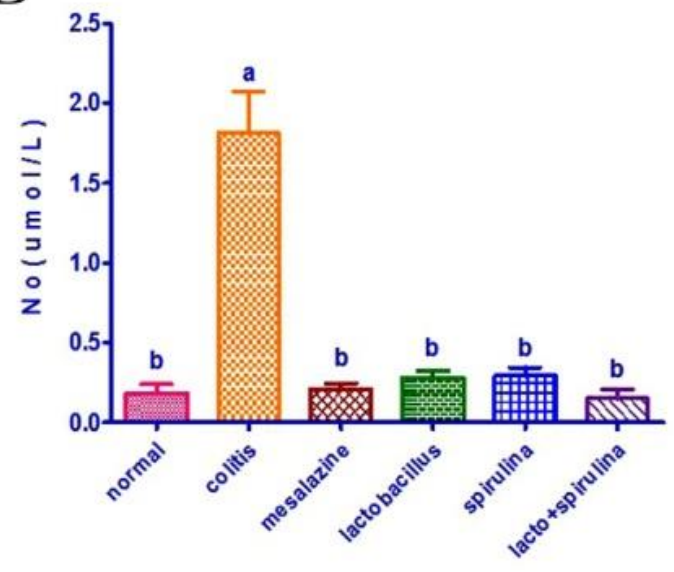

$\mathrm{D}$

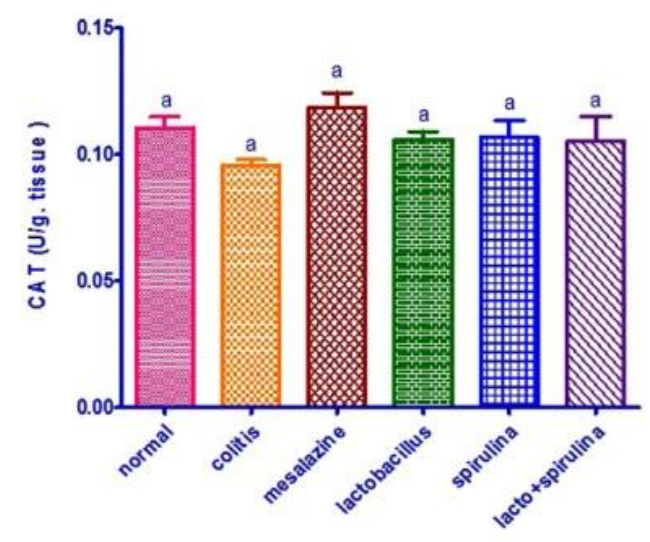

$\mathrm{F}$

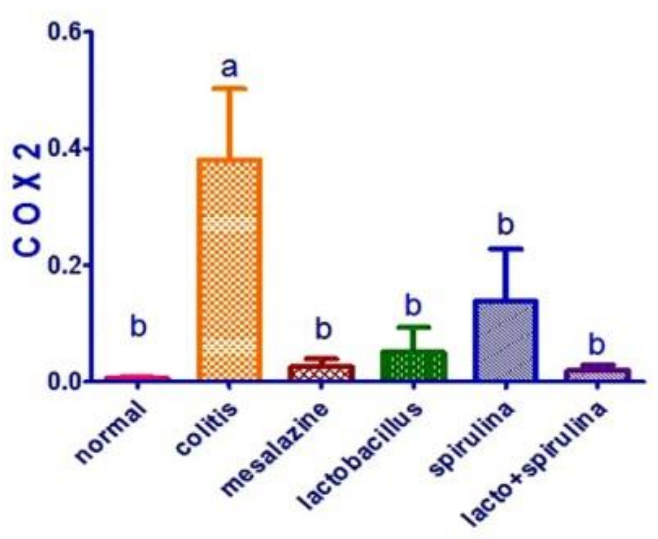

Figure 2: A, B) Lipid peroxidation, C,D) antioxidant biomarkers and E,F) molecular gene expression in control and different treated groups. Data were statistically analyzed as mean \pm SEM. Rows carrying different superscript letters are significantly different at $p \leq 0.05$ 

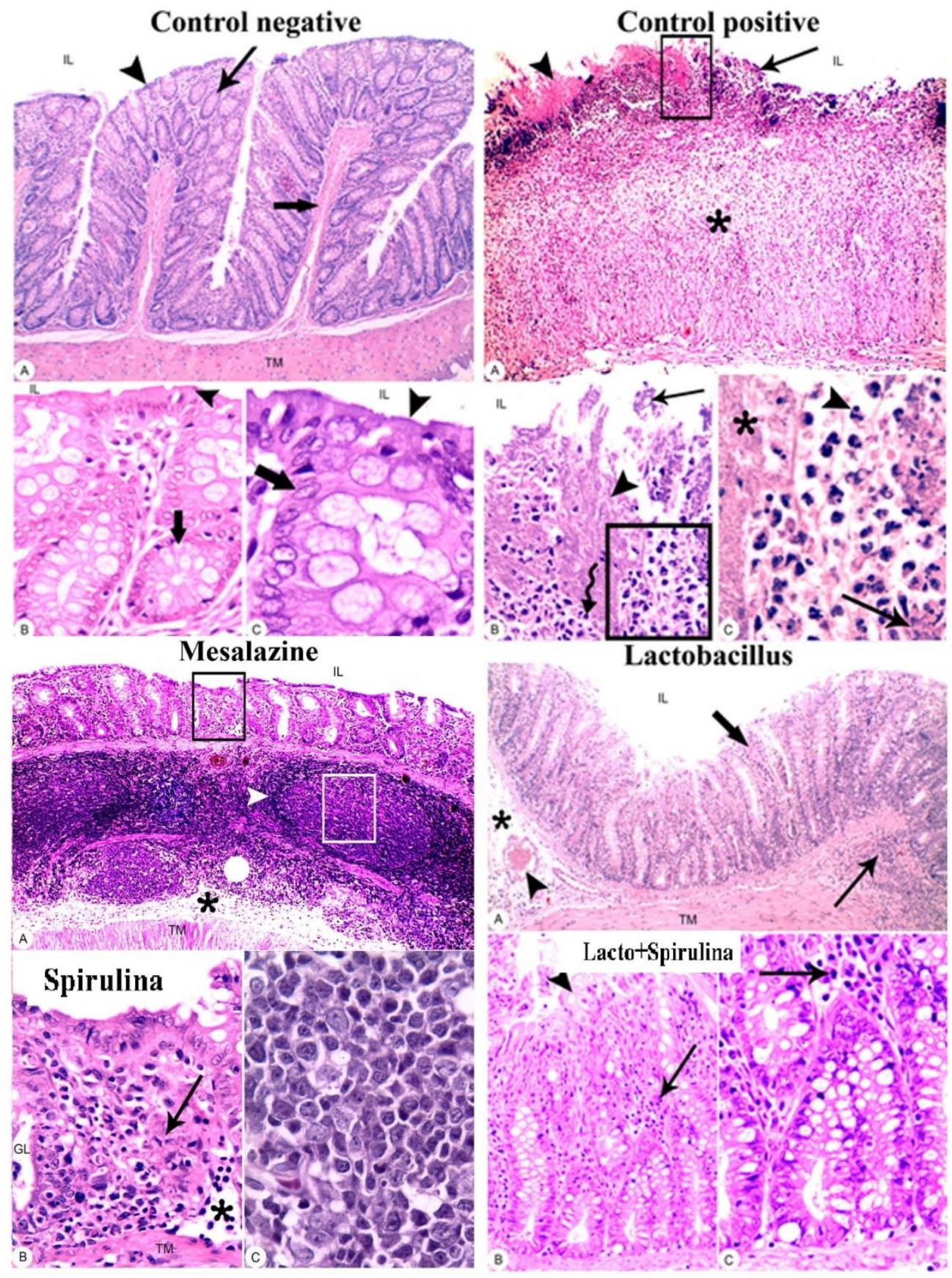

Figure 3: Histopathological feature in control and different treated groups. Microscopic features of colon rats by H\&E stain. 1. Normal group, normal histologic architectures. 2. Acetic acid group (acute chemical colitis): showing necrosis of epithelial surface with deposition of irregular collagen fibers, crypt distortion, and loss of intestinal glands. 3. Mesalazine treated group, colitis: showing patchy mucosalnecrosis, proliferation of submucosal lymphoid elements (lymphocytes, macrophages and plasma cells), and submucosal edema.4. Lactobacillus treated group moderate colitis: showing mononuclear cell infiltration in the mucosa and submucosa, congestion of submucosal blood vessels and edema. 5. Spirulina treated group, mild lymphocytic colitis: showing mononuclear cell infiltration in the mucosa, edema with normal surface epithelium. 6. Lactobacillus+Spirulina treated group, mild lymphocytic colitis: showing mononuclear cell infiltration in the mucosa, with normal surface epithelium 


\section{Discussion}

Ulcerative colitis is an inflammatory condition which cause abdominal pain, bloody diarrhea and mucous in stool(7). Furthermore, weight loss and other many symptoms that differ from person to person and it may be lead to colorectal cancer (45). The study designed to evaluate the effect of some natural agents (Lactobacillus and/or Spirulina) to ameliorate the clinical manifestation of acetic acid (4\%) induced colitis in rats.

The present study exhibited significant increase in DAI and macroscopic damage in control positive rats as compared with the normal negative one. This increase could be referred to loss of appetite, decrease food consumption and feverish conditions which resulted in body weight reduction(46). Others referred this increase in DAI due to high inflammatory response and occasional ulceration that induced bloody diarrhea as confirmed by elevated mortality rate percent $(44.4 \%)$, histopathological lesions and high macroscopic damage score and these results parallel with $(9,47)$.

At the same time, rats of control positive group showed significant increase of colon weight with significant reduction in colon length as compared with non treated one that might be referred to cellular swelling which resulted from shift of extracellular water into the cells associated with neutrophils and macrophage infiltration. Furthermore, cells turgor, submucosal edema, vascular dilatation and goblet cell hyperplasia. Similar result was obtained by $(48,49)$.

Oxidative stress and lipid peroxidation play acritical role in pathogenesis of ulcerative colitis $(50,51)$. Control positive animals revealed marked reduction in CAT and GSH, meanwhile, a significant elevation of MDA and NO was recorded as contrasted with control negative group. These results run parallel with those obtained by (52)

Generation of ROS and free radicals from migrated neutrophils attack the cellular macromolecules and lead to epithelial cell disruption with extensive colon damage $(53,54)$. Furthermore, ROS lead to massive oxidation of cell membrane phospholipids, proteins, and DNA. This oxidation cause further stimulates of more neutrophils and macrophage infiltration to damaged tissue (49).Consequently, intestinal mucosa to regulate ROS levels, have enzymatic and non-enzymatic complex antioxidant defenses mechanism such as reduced glutathione (GSH) and catalase (CAT), which try to heal and repair the damaged cells. Moreover, GSH and CAT were consumed by inflamed colon tissues to neutralize oxidative stress $(55,56)$.

Malondialdehyde (MDA) considered the end result of lipid peroxidation which caused by ROS. Based on that, the elevated MDA in acetic acid (4\%) induced colitis rats referred to the increased lipid peroxidation and high cell damage $(57,58)$.

Nitric oxide (NO) is produced by some inflammatory cells such as granular leukocytes (neutrophils) or granular leukocytes (monocytes, and macrophages) as well as extravascular compartment as epithelial cells from inflamed colon tissue. Thereby, elevated NO content in experimental colitis considered as an index of inflammation(59).

Molecular genes expressions (iNOS and COX-2) are considered important gene expressions in acetic acid induced colitis, and they have synergistic effect to augmented the inflammatory reaction(60). Furthermore, recent investigations reported close interrelationship existing between iNOS and COX-2 expressions at sites of inflammation, and leading to excessive induction of inflammatory mediators which may causing the development of intestinal damage(61).

In this study, colon tissues exposed to acetic acid produced an over expression of iNOS and COX-2messenger as compared with the control negative one, these results were supported by findings of $(62,63)$.

Concerning to inducible nitric oxide synthase (iNOS), it is an enzyme usually expressed during inflammatory reactions(64). Meanwhile, synthesis of large amounts of nitric oxide (NO) content is demonstrated in acute or chronic inflammation, and it produced largely when iNOS expression is increased. 
Synergistic ameliorative effect of Lactobacillus and Spirulina platensis against expermintal colitis in albinorats: ... 563

Overall, elevated of iNOS expression may be an indicator of inflammation progression(10).

Enhancement of COX-2 (inducible cyclooxygenase enzyme) expressions from inflamed colon tissues play an integral role in the pathogenesis of ulcerative colitis $(65,66)$. Moreover, excessive over expressions of COX-2 lead to prostaglandin (PGE) releasing (67), and ROS production which cause further cell injury (65).

Histopathological finding go side by side with the obtained macroscopic damage score, oxidative and anti-oxidative biomarkers in addition to molecular gene expressions, these data were in harmony with those obtained by(68).

Concerning to Mesalazine, it considered positive drug control which inhibit oxidative stress and ROS releasing from inflamed colon tissue. Moreover, its antioxidant (31) antiinflammatory effects (69)reduced tissue damage and modulated mortality rate $(12.5 \%)$.

The current data declared that, gastric intubation of Lactobacillus on acetic acid induced colitis showed marked decrease in DAI in comparison with control positive group. This improvement of DAI could be owed to either increase body weigh by increasing energy efficiency (70) or decrease bloody diarrhea and these results were confirmed by decrease mortality rate percent $(25 \%)$. On the other hand, Lactobacillus supplementation revealed significant decline in macroscopic damage score which was confirmed by reduce colon weight associated with significant enhancement of colon length as contrasted with control positive group (71).

The damage score was ameliorated due to the ability of Lactobacillus to modulate inflammatory response of colon tissue through interferes with innate immune system and adaptive immunity. Therefore, it enhances anti-inflammatory cytokine production (72). Others attributed the reduction of inflammation by Lactobacillus to bacteriocins secretions which act as broad spectrum antimicrobial substances and protect against secondary infections, Consequently decreasing the duration of diarrhea (73). In the other hand, Lactobacil- lus may changepH of the gut flora which leading to reduce inflammatory state of colon(74).

At the same time, lipid peroxidation and antioxidant biomarkers evaluate ability of Lactobacillus to reduce ROS and free radicals from inflamed colon (75). In this study, supplementation of Lactobacillus revealed an improvement of antioxidant biomarkers (GSH and CAT) and decreased in oxidative stress parameters (MDA and NO) as matched with control positive group, these facts were confirmed by result of (76). Multiple experimental studies demonstrated the antioxidative activities of Lactobacillus by secreting enzymatic and non enzymatic anti-oxidant substance and promoting its release from the inflamed colon tissue (77).

Moreover, Lactobacillus enhance the production of particular antioxidant biomolecules, for example, exopolysaccharides (EPSs) which probably useful for elimination of oxidative stress from intestine (78). Consequently decrease lipid peroxidation (MDA) and NO marker from inflamed colon tissue. Finally, it exhibited metal chelating activities which get together with the pathogenesis of most chronic diseases(79). These results were confirmed by significant decrease in iNOS andCOX-2 expression in Lactobacillus supplemented group as matched with control positive group, these data are in harmony with those obtained by $(80)$.

Consistent with this mechanism, histopathological findings of Lactobacillus group were showed moderate colitis. This finding agrees with (12). Therefore, Lactobacillus had many therapeutic benefits and was used as vehicles for treatment of gastrointestinal diseases (81)

In this experiment, Spirulina supplementation played great role in relieving the incidence of induced colitis. Significant enhancement in DAI and macroscopic damage score were recorded in Spirulina group as compared with control positive group, this effect could be explained by the high protein content, amino acids, vitamins (vitamin B complex) and folic acid which induce an increase in nutri- 
tional value of this algae and promote weight gain (27).

Similarly, a significant decline in bloody diarrhea was found in Spirulina group reach to (0\%) may be due to mucopolysachharids content which makes building blocks of colon cell membranes and accelerates healing of colon tissue (30) These results were confirmed by decreased mortality rate to $25 \%$ and histopathological findings. Furthermore, gastric intubation of Spirulina in acetic acid induced colitis showed a marked decline in colon weight with significant increase in colon length as contrasted with control positive group. This improvement could be referred to ability of Spirulina to manage the inflammatory conditions and oxidative damages (82). Phycocyanin present in Spirulina considers anti-inflammatory ingredients of it, which decrease production of intracellular ROS and histamine from mast cell, inhibit inflammatory cell infiltration specially neutrophil and reduced edema index in the induced inflammation $(83,84)$. Besides that, Spirulina has excellent antioxidative properties and preservative effects to structural integrity of colon tissue(85). In present study, Spirulina supplementation showed improvement in CAT and GSH and significant decrease in NO and MDA in comparison with control positive group. These results confirmed by molecular RNA expression of iNOS and COX-2 which showed significant decrease in contrast with control positive group. The antioxidant antiinflammatory effects of Spirulina could be attributed to its content of phycocyanin and $\beta$ carotene which have capability to scavenge free radicals and ROS from inflamed colon tissue (86).

In the same way, Spirulina decreased inflammatory mediators and inflammatory cytokines (IL-1 $\beta$, IL-6, and IL-12) releasing from inflamed colon (87). Therefore, it plays a fundamental role in UC improvement. Moreover, histopathological finding of Spirulina showed mild colitis, and this result supported by finding of (32).

Noteworthy, the combination of Spirulina and Lactobacillus in acetic acid induced colitis afforded a higher protection and more effectiveness than each one alone, this result was confirmed by recording the lowest mortality rate $(12.5 \%)$, molecular expressions and histopathological findings similar to positive drug control (Mesalazine), that owed to an improvement growth performance and health condition (88). Spirulina not only modulate inflammatory response of acetic acid induced colitis, but also it consider as importance nutritional point for Lactobacillus due to rich source of protein content, amino acids, vitamins etc which could be needed to nourishment of Lactobacillus and improve intestinal colonization $(89,90)$. Over all, Spirulina has growth promoting effect on Lactobacillus to reduce the inflammatory effect of ulcerative colitis.

\section{Conclusion}

In conclusion, the protective effect of Lactobacillus and /or Spirulina against experimental colitis in rats could be directly attributed to scavenging ROS, inhibiting lipid peroxidation and suppressing NO releasing. Furthermore, Lactobacillus and Spirulina have synergistic protective effect on colon tissue and could be used in combination to ameliorate ulcerative colitis.

\section{Conflict of interest}

The authors declare that they have no conflict of interest.

\section{References}

1. Shiina T, Shima T, Naitou K, Nakamori H, Sano Y, Horii K, et al. Actions of probiotics on trinitrobenzenesulfonic acid-induced colitis in rats. BioMed Research International. 2015;2015.

2. Coskun M. Intestinal epithelium in inflammatory bowel disease. Frontiers in medicine. 2014; 1: 24.

3. Molodecky NA, Soon S, Rabi DM, Ghali WA, Ferris M, Chernoff G, et al. Increasing incidence and prevalence of the inflammatory bowel diseases with time, based on systematic review. Gastroenterology. 2012;142(1): 46-54. e42.

4. Laroui H, Ingersoll SA, Liu HC, Baker MT, Ayyadurai S, Charania MA, et al. Dextran sodium sulfate (DSS) induces colitis in mice by forming nano-lipocomplexes with medium-chain-length 
Synergistic ameliorative effect of Lactobacillus and Spirulina platensis against expermintal colitis in albinorats: ... 565

fatty acids in the colon. PloS one. 2012; 7(3): e32084.

5. Oliveira Lgd, Cunha Ald, Duarte Ac, Castañon Mcmn, Chebli Jmf, Aguiar Jakd. Positive correlation between disease activity index and matrix metalloproteinases activity in a rat model of colitis. Arquivos de gastroenterologia. 2014;51(2): 10712.

6. Silveira ALM, Ferreira AVM, de Oliveira MC, Rachid MA, da Cunha Sousa LF, dos Santos Martins F, et al. Preventive rather than therapeutic treatment with high fiber diet attenuates clinical and inflammatory markers of acute and chronic DSS-induced colitis in mice. European journal of nutrition. 2017; 56(1): 179-91.

7. Najafi A, Motaghi E, Hosseini MJ, GhasemiPirbaluti M. The effect of sodium valproate on acetic acid-induced colitis in rats. Inflammopharmacology. 2017;25(1): 137-45.

8. Ashry EE, Abdellatief RB, Mohamed AE, Kotb HI. Protective Effect of Ketamine against Acetic Acid-Induced Ulcerative Colitis in Rats. Pharmacology \& Pharmacy. 2016;7(01): 9.

9. Guerra GC, Araújo AA, Lira GA, Melo MN, Souto KK, Fernandes D, et al. Telmisartan decreases inflammation by modulating TNF- $\alpha$, IL-10, and RANK/RANKL in a rat model of ulcerative colitis. Pharmacological Reports. 2015;67(3): 5206.

10. Bezerra GB, de Souza LdM, dos Santos AS, de Almeida GKM, Souza MTS, Santos SL, et al. Hydroalcoholic extract of Brazilian red propolis exerts protective effects on acetic acid-induced ulcerative colitis in a rodent model. Biomedicine \& Pharmacotherapy. 2017;85: 687-96.

11. Ali AA, Al Haleem ENA, Khaleel SA-H, Sallam AS. Protective effect of cardamonin against acetic acid-induced ulcerative colitis in rats. Pharmacological Reports. 2017; 69(2): 268-75.

12. Toumi R, Soufli I, Rafa H, Belkhelfa M, Biad A, Touil-Boukoffa C. Probiotic bacteria lactobacillus and bifidobacterium attenuate inflammation in dextran sulfate sodium-induced experimental colitis in mice. International journal of immunopathology and pharmacology. 2014;27(4): 615-27.

13. Wang Y-h, Huang Y. Effect of Lactobacillus acidophilus and Bifidobacterium bifidum supplementation to standard triple therapy on Helicobacter pylori eradication and dynamic changes in intestinal flora. World Journal of Microbiology and Biotechnology. 2014;30(3): 847-53.

14. Lorén V, Manyé J, Fuentes MC, Cabré E, Ojanguren I, Espadaler J. Comparative effect of the I3. 1 probiotic formula in two animal models of colitis. Probiotics and antimicrobial proteins. 2017;9(1): 71-80.

15. Kaur IP, Kuhad A, Garg A, Chopra K. Probiotics: delineation of prophylactic and therapeutic benefits. Journal of medicinal food. 2009;12(2): 219-35.

16. Islam SU. Clinical uses of probiotics. Medicine. 2016;95(5).

17. Kostyukevich Y, Vlaskin M, Vladimirov G, Zherebker A, Kononikhin A, Popov I, et al. The investigation of the bio-oil produced by hydrothermal liquefaction of Spirulina platensis using ultrahigh resolution Fourier transform ion cyclotron resonance mass spectrometry. European Journal of Mass Spectrometry. 2017; 23(2): 83-8.

18. González-Torres L, Vázquez-Velasco $\mathrm{M}$, Olivero-David R, Bastida S, Benedí J, González $\mathrm{RR}$, et al. Glucomannan and glucomannan plus spirulina added to pork significantly block dietary cholesterol effects on lipoproteinemia, arylesterase activity, and CYP7A1 expression in Zucker fa/fa rats. Journal of physiology and biochemistry. 2015; 71 (4): 773-84.

19. Zhang L-X, Cai C-E, Guo T-T, Gu J-W, Xu H-L, Zhou Y, et al. Anti-cancer effects of polysaccharide and phycocyanin from Porphyra yezoensis. Journal of Marine Science and Technology. 2011; 19(4): 377-82.

20. Murugan T. Screening for antifungal and antiviral activity of C-phycocyanin from Spirulina Platensis. 2011.

21. Pankaj PP, Varma M. Potential role of Spirulina platensis in maintaining blood parameters in alloxan induced diabetic mice. Int J Pharm Pharm Sci. 2013;5: 450-6.

22. Basha OM, Hafez RA, El-Ayouty YM, Mahrous KF, Bareedy MH, Salama AM. CPhycocyanin inhibits cell proliferation and may induce apoptosis in human HepG2 cells. Egypt $\mathbf{J}$ Immunol. 2008; 15(2): 161-7.

23. Elzawahry ZA, Abass MA, El-Haleem MRA, Hamid RAA, Atteia HH. Spirulina protects against tacrolimus-induced hepatic and renal toxicity in rats: A biochemical and histological study. Journal of Toxicology and Environmental Health Sciences. 2016;8 (7): 46-56.

24. Khan M, Shobha JC, Mohan IK, Naidu MUR, Sundaram C, Singh S, et al. Protective effect of Spirulina against doxorubicin-induced cardiotoxicity. Phytotherapy Research. 2005; 19(12): 1030-7.

25. Gur CS, Erdogan DK, Onbasilar I, Atilla P, Cakar N, Gurhan ID. In vitro and in vivo investiga- 
tions of the wound healing effect of crude Spirulina extract and C-phycocyanin. Journal of Medicinal Plants Research. 2013; 7(8): 425-33.

26. Nagaoka S, Shimizu K, Kaneko H, Shibayama F, Morikawa K, Kanamaru Y, et al. A novel protein C-phycocyanin plays a crucial role in the hypocholesterolemic action of Spirulina platensis concentrate in rats. The Journal of nutrition. 2005; 135(10): 2425-30.

27. Deng R, Chow TJ. Hypolipidemic, antioxidant, and antiinflammatory activities of microalgae Spirulina. Cardiovascular therapeutics. 2010;28(4).

28. Kuriakose GC, Kurup MG. Hepatoprotective effect of Spirulina lonar on paracetamol induced liver damage in rats. Asian J Exp Biol Sci. 2010;1(3): 614-23.

29. Benedetti S, Benvenuti F, Pagliarani S, Francogli S, Scoglio S, Canestrari F. Antioxidant properties of a novel phycocyanin extract from the blue-green alga Aphanizomenon flos-aquae. Life sciences. 2004;75(19): 2353-62.

30. Somchit MN, Mohamed NA, Ahmad Z, Zakaria ZA, Shamsuddin L, Omar-Fauzee M, et al. Anti-inflammatory and anti-pyretic properties of Spirulina platensis and Spirulina lonar: a comparative study. Pakistan journal of pharmaceutical sciences. 2014;27(5): 1277-80.

31. Moura RM, Hartmann RM, Licks F, Schemitt EG, Colares JR, do Couto Soares M, et al. Antioxidant effect of mesalazine in the experimental colitis model induced by acetic acid. Journal of Coloproctology (Rio de Janeiro). 2016;36(3): 139-48.

32. Abdel-Daim MM, Farouk SM, Madkour FF, Azab SS. Anti-inflammatory and immunomodulatory effects of Spirulina platensis in comparison to Dunaliella salina in acetic acid-induced rat experimental colitis. Immunopharmacology and immunotoxicology. 2015;37(2): 126-39.

33. Al-Rejaie SS, Abuohashish HM, Al-Enazi MM, Al-Assaf AH, Parmar MY, Ahmed MM. Protective effect of naringenin on acetic acidinduced ulcerative colitis in rats. World Journal of Gastroenterology: WJG. 2013;19(34): 5633.

34. Fattahian E, Hajhashemi V, Rabbani M, Minaiyan M, Mahzouni P. Anti-inflammatory effect of amitriptyline on ulcerative colitis in normal and reserpine-induced depressed rats. Iranian journal of pharmaceutical research: IJPR. 2016;15(Suppl): 125.

35. Dodda D, Chhajed R, Mishra J. Protective effect of quercetin against acetic acid induced inflammatory bowel disease (IBD) like symptoms in rats: Possible morphological and biochemical al- terations. Pharmacological Reports. 2014;66(1): 169-73.

36. Murthy S, Cooper HS, Shim H, Shah RS, Ibrahim SA, Sedergran DJ. Treatment of dextran sulfate sodium-induced murine colitis by intracolonic cyclosporin. Digestive diseases and sciences. 1993;38(9): 1722-34.

37. Motta J-P, Flannigan KL, Agbor TA, Beatty JK, Blackler RW, Workentine ML, et al. Hydrogen sulfide protects from colitis and restores intestinal microbiota biofilm and mucus production. Inflammatory bowel diseases. 2015;21(5): 1006-17.

38. Nagy ZT. A hands-on overview of tissue preservation methods for molecular genetic analyses. Organisms Diversity \& Evolution. 2010;10(1): 91-105.

39. Ohkawa H, Ohishi N, Yagi K. Assay for lipid peroxides in animal tissues by thiobarbituric acid reaction. Analytical biochemistry. 1979;95(2): 351-8.

40. Ingram G, Montgomery $\mathrm{H}$, Dymock JF, Henneberry G, Baker B, Forbes J, et al. Notes. Analyst. 1961;86(1023): 411-22.

41. Saleh A A, El-Magd M A. Beneficial effects of dietary silver nanoparticles and silver nitrate on broiler nutrition, Environmental Science and Pollution Research 2018; 25(27): 2703127038.

42. Owens C, Belcher R. A colorimetric micromethod for the determination of glutathione. Biochemical Journal. 1965;94(3): 705.

43. Kim YH, Kwon H-S, Kim DH, Cho HJ, Lee HS, Jun J-G, et al. Piceatannol, a stilbene present in grapes, attenuates dextran sulfate sodiuminduced colitis. International immunopharmacology. 2008;8(12): 1695-702.

44. Dries DJ. Histological and histochemical methods: theory and practice. Shock. 2008;30 (4): 481.

45. Kim ER, Chang DK. Colorectal cancer in inflammatory bowel disease: the risk, pathogenesis, prevention and diagnosis. World Journal of Gastroenterology: WJG. 2014;20(29): 9872.

46. Minaiyan M, Hajhashemi V, Rabbani M, Fattahian E, Mahzouni P. Evaluation of anti-colitic effect of fluvoxamine against acetic acid-induced colitis in normal and reserpinized depressed rats. European journal of pharmacology. 2015;746: 293300.

47. Adjadj M, Boumerfeg S, Charef N, Baghiani A, Khennouf S, Arrar L, et al. Protective Effect of Paronychia argentea L. on Acetic Acid Induced Ulcerative Colitis in Mice by Regulating Antioxidant Parameters and inflammatory Markers. 
Synergistic ameliorative effect of Lactobacillus and Spirulina platensis against expermintal colitis in albinorats: ... 567

48. D’Argenio G, Mazzone G, Tuccillo C, Ribecco MT, Graziani G, Gravina AG, et al. Apple polyphenols extract (APE) improves colon damage in a rat model of colitis. Digestive and Liver Disease. 2012;44(7): 555-62.

49. Krishnan M, Jayaraj RL, Megala J, Elangovan N. Antioxidant mediated antiulcer effect of Eupatorium triplinerve Vahl against acetic acid induced ulcerative colitis in mice. Biomedicine \& Aging Pathology. 2014;4(2): 153-60.

50. Prabhu V, Guruvayoorappan C. Protective effect of marine mangrove Rhizophora apiculata on acetic acid induced experimental colitis by regulating anti-oxidant enzymes, inflammatory mediators and nuclear factor-kappa B subunits. International immunopharmacology. 2014;18(1): 124-34.

51. El Morsy EM, Kamel R, Ahmed MA. Attenuating effects of coenzyme Q10 and amlodipine in ulcerative colitis model in rats. Immunopharmacology and immunotoxicology. 2015;37(3): 24451.

52. Pasala PK, Alluri R, Mavulati SC, Mailavaram RP, Shaik K, Konduri P. Protective Effect of A.

53. Haskó G, Linden J, Cronstein B, Pacher P. Adenosine receptors: therapeutic aspects for inflammatory and immune diseases. Nature reviews Drug discovery. 2008;7(9): 759.

54. Mohamed A, Metwally N, Mohamed S, Hassan E. Protective capacity of butanolic extract of myoporum laetum against oxidative stress and immune disorder induced tissue damage in profenofos intoxicated rats. International Journal of Academic Research. 2010;2(2).

55. Subudhi U, Chainy GB. Expression of hepatic antioxidant genes in 1-thyroxine-induced hyperthyroid rats: regulation by vitamin $\mathrm{E}$ and curcumin. Chemico-Biological Interactions. 2010;183(2): 304-16.

56. Kandhare AD, Raygude KS, Ghosh P, Ghule AE, Gosavi TP, Badole SL, et al. Effect of hydroalcoholic extract of Hibiscus rosa sinensis Linn. leaves in experimental colitis in rats. Asian Pacific journal of tropical biomedicine. 2012;2(5): 337-44.

57. Karbiner MS, Sierra L, Minahk C, Fonio $\mathrm{MC}$, de Bruno MP, Jerez S. The role of oxidative stress in alterations of hematological parameters and inflammatory markers induced by early hypercholesterolemia. Life sciences. 2013;93(15): 5038 .

58. Kumar CS, Reddy KK, Reddy AG, Vinoth A, Boobalan G, Rao G. Protective effect of Lactobacillus plantarum 21, a probiotic on trinitroben- zenesulfonic acid-induced ulcerative colitis in rats. International immunopharmacology. 2015;25(2): 504-10.

59. Gillberg L, Varsanyi M, Sjöström M, Lördal M, Lindholm J, Hellström PM. Nitric oxide pathway-related gene alterations in inflammatory bowel disease. Scandinavian journal of gastroenterology. 2012;47(11): 1283-98.

60. Sakthivel K, Guruvayoorappan C. Amentoflavone inhibits iNOS, COX-2 expression and modulates cytokine profile, NF- $\mathrm{KB}$ signal transduction pathways in rats with ulcerative colitis. International immunopharmacology. 2013;17(3): 90716.

61. Ya Sklyarov A, Panasyuk N, Fomenko I. Role of nitric oxide-synthase and cyclooxygenase/lipooxygenase systems in development of experimental ulcerative colitis. Journal of Physiology and Pharmacology. 2011;62(1): 65.

62. Sadar SS, Vyawahare NS, Bodhankar SL. Ferulic acid ameliorates TNBS-induced ulcerative colitis through modulation of cytokines, oxidative stress, iNOs, COX-2, and apoptosis in laboratory rats. EXCLI journal. 2016;15: 482.

63. Wu X, Song M, Gao Z, Sun Y, Wang M, Li F, et al. Nobiletin and its colonic metabolites suppress colitis-associated colon carcinogenesis by down-regulating iNOS, inducing antioxidative enzymes and arresting cell cycle progression. The Journal of nutritional biochemistry. 2017;42: 1725.

64. Naito Y, Takagi T, Handa O, Ishikawa T, Nakagawa S, Yamaguchi T, et al. Enhanced intestinal inflammation induced by dextran sulfate sodium in tumor necrosis factor-alpha deficient mice. Journal of gastroenterology and hepatology. 2003;18(5): 560-9.

65. Takedatsu H, Taylor KD, Mei L, McGovern DP, Landers CJ, Gonsky R, et al. Linkage of Crohn's disease-related serological phenotypes: NFKB1 haplotypes are associated with anti-CBir1 and ASCA, and show reduced NF- $\mathrm{\kappa B}$ activation. Gut. 2009;58(1): 60-7.

66. Carroll IM, Andrus JM, Bruno-Bárcena JM, Klaenhammer TR, Hassan HM, Threadgill DS. Anti-inflammatory properties of Lactobacillus gasseri expressing manganese superoxide dismutase using the interleukin 10-deficient mouse model of colitis. American Journal of PhysiologyGastrointestinal and Liver Physiology. 2007;293 (4): G729-G38.

67. Rogler G, Andus T. Cytokines in inflammatory bowel disease. World journal of surgery. 1998;22(4): 382-9. 
68. Baumgart D, Baumgart DC. Crohn's Disease and Ulcerative Colitis: Springer; 2017.

69. Zeng C, Xiao J-H, Chang M-J, Wang J-L. Beneficial effects of THSG on acetic acid-induced experimental colitis: involvement of upregulation of PPAR- $\gamma$ and inhibition of the Nf-Kb inflammatory pathway. Molecules. 2011;16(10): 8552-68.

70. Million M, Angelakis E, Paul M, Armougom F, Leibovici L, Raoult D. Comparative metaanalysis of the effect of Lactobacillus species on weight gain in humans and animals. Microbial pathogenesis. 2012;53(2): 100-8.

71. Fernandez EM, Valenti V, Rockel C, Hermann C, Pot B, Boneca IG, et al. Antiinflammatory capacity of selected lactobacilli in experimental colitis is driven by NOD2-mediated recognition of a specific peptidoglycan-derived muropeptide. Gut. 2011: gut. 2010.232918.

72. Dos Santos T, Melo T, Santos D, Rezende R, Dias J, Romano C. Efficacy of oral administration of lactic acid bacteria isolated from cocoa in a fermented milk preparation: reduction of colitis in an experimental rat model. Genet Mol Res. 2016;15(3).

73. Ciszek-Lenda $M$, Nowak B, Śróttek $M$, Gamian A, Marcinkiewicz J. Immunoregulatory potential of exopolysaccharide from Lactobacillus rhamnosus KL37. Effects on the production of inflammatory mediators by mouse macrophages. International journal of experimental pathology. 2011;92(6): 382-91.

74. AFRC RF. Probiotics in man and animals. Journal of Applied Microbiology. 1989;66(5): 36578.

75. Motterlini R, Foresti R, Bassi R, Green CJ. Curcumin, an antioxidant and anti-inflammatory agent, induces heme oxygenase-1 and protects endothelial cells against oxidative stress. Free Radical Biology and Medicine. 2000;28(8): 1303-12.

76. Spyropoulos BG, Misiakos EP, Fotiadis C, Stoidis CN. Antioxidant properties of probiotics and their protective effects in the pathogenesis of radiation-induced enteritis and colitis. Digestive diseases and sciences. 2011;56(2): 285-94.

77. de LeBlanc AdM, LeBlanc JG, Perdigon G, Miyoshi A, Langella P, Azevedo V, et al. Oral administration of a catalase-producing Lactococcus lactis can prevent a chemically induced colon cancer in mice. Journal of Medical Microbiology. 2008;57(1): 100-5.

78. Kodali VP, Sen R. Antioxidant and free radical scavenging activities of an exopolysaccharide from a probiotic bacterium. Biotechnology journal. 2008;3(2): 245-51.
79. Lee J, Hwang K-T, Heo M-S, Lee J-H, Park K-Y. Resistance of Lactobacillus plantarum KCTC 3099 from Kimchi to oxidative stress. Journal of medicinal food. 2005;8(3): 299-304.

80. Peran L, Sierra S, Comalada M, LaraVilloslada F, Bailón E, Nieto A, et al. A comparative study of the preventative effects exerted by two probiotics, Lactobacillus reuteri and Lactobacillus fermentum, in the trinitrobenzenesulfonic acid model of rat colitis. British Journal of Nutrition. 2007;97(1): 96-103.

81. Csutak O, Sarbu I. Genetically Modified Microorganisms: Harmful or Helpful? Genetically Engineered Foods: Elsevier; 2018. p. 143-75.

82. Abdel-Daim MM. Pharmacodynamic interaction of Spirulina platensis with erythromycin in Egyptian Baladi bucks (Capra hircus). Small Ruminant Research. 2014;120(2): 234-41.

83. Gonzalez R, Rodriguez S, Romay C, González A, Armesto J, Remirez D, et al. Antiinflammatory activity of phycocyanin extract in acetic acid-induced colitis in rats. Pharmacological research. 1999;39(1): 55-9.

84. González R, González A, Remirez D, Romay C, Rodriguez S, Ancheta O, et al. Protective effects of phycocyanin on galactosamineinduced hepatitis in rats. Biotechnology Aplicada. 2003;20: 107-10.

85. Sharma K, Upreti N, Sharma S, Sharma S. Protective effect of Spirulina and tamarind fruit pulp diet supplement in fish (Gambusia affinis Baird \& Girard) exposed to sublethal concentration of fluoride, aluminum and aluminum fluoride. 2012.

86. Vo T-S, Ryu B, Kim S-K. Purification of novel anti-inflammatory peptides from enzymatic hydrolysate of the edible microalgal Spirulina maxima. Journal of Functional Foods. 2013;5(3): 1336-46.

87. Katsuura $S$, Imamura $\mathrm{T}$, Bando $\mathrm{N}$, Yamanishi R. $\beta$-Carotene and $\beta$-cryptoxanthin but not lutein evoke redox and immune changes in RAW264 murine macrophages. Molecular nutrition \& food research. 2009;53(11): 1396-405.

88. Ramakrishnan CM, Haniffa M, Manohar M, Dhanaraj M, Arockiaraj AJ, Arunsingh S. Effects of probiotics and spirulina on survival and growth of juvenile common carp (Cyprinus carpio). 2008.

89. Parada JL, de Caire GZ, de Mule MCZ, de Cano MMS. Lactic acid bacteria growth promoters from Spirulina platensis. International journal of food microbiology. 1998;45(3): 225-8.

90. Varga L, Szigeti J, Kovács R, Földes T, Buti S. Influence of a Spirulina platensis biomass 
on the microflora of fermented ABT milks during Parkinsons disease. Journal of neurochemistry. storage (R1). Journal of dairy science. 2002;85(5): 1031-8. 2010;114(6): 1687-700.

91. Villarán RF, Espinosa-Oliva AM, Sarmiento M, De Pablos RM, Argüelles S, DelgadoCortés MJ, et al. Ulcerative colitis exacerbates lipopolysaccharide-induced damage to the nigral dopaminergic system: potential risk factor in

92. Bhatia HS, Candelario-Jalil E, de Oliveira ACP, Olajide OA, Martínez-Sánchez G, Fiebich BL. Mangiferin inhibits cyclooxygenase- 2 expression and prostaglandin E2 production in activated rat microglial cells. Archives of biochemistry and biophysics. 2008;477(2): 253-8. 